\title{
The ‘Revenge’ of Political Geographers
}

\author{
Marco Antonsich \\ University of Birmingham
}

Kaplan (2009) is back and this time with a new, mesmerizing idea: 'it's geography, baby'. According to the illustrious foreign correspondent of The Atlantic, we should not look too far away to explain the complexity of present world politics. The answer lies just there, under our feet. It is in fact geography which largely determines world political events. To be deaf to its insights would lead us (i.e., America and the West) to follow our idea(l)s in a reckless way. The analogy with the 'Big Mac' is clear. Like the 'airy cherub' of Mackinder at Versailles in 1919, Kaplan's whispered message reads today all the same: don't let your idealistic aspirations for democracy and freedom take over the 'reality’ of geography. The price to pay, in flesh and blood, would be too high - Iraq stands as an example.

Kaplan's argument is pretty straightforward. Twenty years after the fall of the Berlin Wall, which triggered euphoric feelings for a new dawn of global peace, we are back to business as usual. It is once again realism which can guide us in this precarious world. Freedom and democracy means nothing if order is not in place (p. 98). Brushing the dust off from Malthus, Mahan, Mackinder, and Spykman - and, more surprisingly, also from Braudel and Canetti (who I am not sure would be happy to be put in such a coterie) Kaplan presents us with a classic geopolitical landscape. Eurasia is at the center, as usually. Yet, what Kaplan's call Eurasia is actually Mackinder’s inner crescent (or Spykman’s rimland). Very little of Central Asia and Russia is, in fact, in the picture. All attention goes to the usual suspects - those states from the Mediterranean's eastern shores to the Indian subcontinent, which form the notorious 'arc of crisis' of US realism. These are the trouble-makers, the source of chaos which threats the world... well, the Western world, as in fact Kaplan seems not very much concerned with, for instance, Africa or 
South America. Whichever troubles are here, they would not bother the West and its security. Driven by a 'healthy' realist perspective, Kaplan in fact cares only about his world (USA and the West). The sufferance caused by the instability within the 'arc of crisis' is not, per se, a matter of concern. What matters, instead, is how the instability and the potential geopolitical change within this region might threaten 'us', both by disrupting our socio-economic life and by challenging - China and India, more than Russia - the primacy of the West(ern empire).

As a way to understand and predict these threats, Kaplan turns to geography. Contrary to academic geographers, for whom geography is about the complexity of interrelated human and non-humans factors, Kaplan's idea of geography echoes the one which many of us might have heard the time we have dared mentioning to someone our profession: 'ah, you study rivers, capitals and things like that'... Kaplan's geography resonates with the same basic elements of our old, idiographic discipline. In his own words: "The physical features of the landscape may be the only reliable guides left to understanding the shape of future conflict” (p. 102).

Even if he does not mention his name, Kaplan’s conceptual model reproduces Cohen’s (1964) idea of shatter-belts. Kaplan’s “geographic logic”, in fact, which can give us precious "insights" to decipher world politics, relies on the idea that "like rifts in the Earth's crust that produce physical instability", there are areas in the world which "are more prone to conflicts than others” (p. 102). Nothing new, as said, since the same idea was put forward by Cohen almost half-century ago. Yet, rather surprisingly, Kaplan's rifts are all localized within a rather narrow strip, namely Eurasia (i.e., the rimland). These rifts - left undiscussed by Kaplan - determine four 'shatter zones': the Indian subcontinent, the Arabian Peninsula, the Fertile Crescent, and the Persian core. These are areas which "threaten to implode, explode, or maintain a fragile equilibrium” and which, rather evocatively, Kaplan labels "the greater Middle East”. The use of this term is not accidental, as it obviously aims to extend the idea of instability, often associated with the Middle East, to the whole strip.

Kaplan's geopolitical view relies essentially on "rivers, deserts, mountains, and other enduring facts of geography" to determine whether a state's boundaries are "artificial” or not and, therefore, whether a state is "illogical" (i.e, against geography, that is to say 
nature) or not. Accordingly, since the landscape between India and Bangladesh is the same on both sides of the border, it is hard for Kaplan not to predict some geopolitical “metamorphose” in this region. 'Tell me your borders and I will tell your fate' - a pretty scary scenario if we consider how many states, even in the West, have "artificial" boundaries.

Kaplan's piece offers geographers with a rich terrain for criticism. Feminist authors might stress his masculine gaze, which sees the threat haunted among crowds of young men in overcrowded peripheries. They might also lament the lack of human agency, and therefore the absence of any political accountability and responsibility. Similarly, critical geopolitics' authors might discard Kaplan’s geographical determinism for its blindness to what make geography intelligible, i.e. language and discourse. Additionally, they could criticize his Western-centric, state-centric, and conflict-driven view. Classic geopolitics' students might instead conclude that, despite Kaplan’s goal “to revise Mackinder for our time” (p. 100), particularly by stressing the connectivity between the heartland and the rimland, his analysis does not present any new, original insight. Moreover, they could also question his inconsistency in contrasting geography and ideas, when he actually seems to value both. Or, again, they could ask why Korea - one of the most debated 'shatter zone' of our time - is not in the picture.

My aim, however, is not to simply offer a critical reading of the latest geopolitical discourse available on the market. Although I believe that it is always important to confront this type of universalistic/deterministic certitudes with a critical spirit, I also believe that the role of political geographers should not confine itself within a mere deconstructivist move. Nobody doubts, I think, that political geographers know well how to critically engage geopolitical representations. Past critiques of Kaplan (Dalby, 1996; Dalby, 2007), as well as Barnett (Roberts et al., 2003) and Friedman (Sparke, forthcoming) - not to mention the long list of critiques of Fukuyama, Ohmae, and Huntington - stand as good examples. Yet, the risk is that academic geographers might content themselves with a role of critics of others' geopolitical representations rather than proposing concrete alternative ways to deal with the here and now of geopolitical problems. For Blomley (2006), the job of critical geographers has indeed become "a little too easy”. The usual 'formula' is one of first showing a righteous wrath at oppressive 
power relations, then moving to their meticulous critique, and finally concluding by "a pious appeal to progressive/emancipatory/liberatory alternatives, without specifying these in detail” (ibid.: 88).

In its simplified argument, The Revenge of Geography puts political geographers in front of a challenging question: what do we know better and how can we make our more informed geographical knowledge count in policy-making decisions? Since the discursive turn, the focus in political geography has increasingly switched from studies aimed at 'analyzing' reality (O' Loughlin and van der Wusten, 1987) to studies aimed at 'problematizing' it (Ó Tuathail, 1987). Moreover, political geographers have increasingly avoided dealing with politics with the big 'P' (i.e., the state) to privilege instead the little 'p’ of everyday life, social movements, local actors, etc. (Flint, 2003; Low, 2003). While all this has enriched our discipline and our critical understanding of the world, it has also generated a void of knowledge, which comes then to be filled by people like Kaplan and their 'one size fits all' recipes.

I certainly agree with Toal (2003: 655) that we should contribute to "a public political culture that demands, requires and values grounded geographical knowledge over abstract geopolitical sloganizing”. Yet, we should also not forget that people like Kaplan knows the world by foot more than many among us. A public political culture, 'thick' with geographical knowledge, might therefore not always be enough. An alternative which political geographers should then consider is to engage directly with the big ' $\mathrm{P}$ '. As put by a political geographer who has to confront daily with the harshness of the 'real world' (Newman 2004), this alternative means to find the ways to bridge the gap between 'us' (academic geographers) and 'them' (statesmen, diplomats, etc.). " "If we believe that we understand the complex processes of structural change which are taking place in global relations, we should not shy away from taking a proactive stance on a range of geopolitical issues [...]” (ibid.: 630). This, I would argue, would be the 'revenge' of political geographers. To be able to talk to the big 'P', without feeling sinful (Agnew 2004: 635) or ambitious (Mamadouh and Dijkink, 2006: 354).

\footnotetext{
${ }^{1}$ Interestingly, as a way to bridge this gap, Foreign Policy will soon host the replies of some political geographers to Kaplan's article.
} 
To be true, as O’Loughlin ( 2000) observes, it might be hard to make a 'thick' geographical knowledge work in a world where order and regularity are usually wanted. Yet, this should not refrain us to reflect on the value added of our knowledge (Agnew, 2003: 606; Bassin, 2004: 626) and on how we can make this world a better place. As Newman (2004: 630) argues, "it is time to show that our geopolitics can extend beyond the realms of the ivory tower and even make an impact where it counts”. Without abandoning the work on and with the little 'p', political geographers should explore the ways in which the big ' $\mathrm{P}$ ' might become an interlocutor in a conversation which goes beyond the logic of realism and exclusive national interests. In an epoch of 'yes, we can' maybe this is an alternative worth exploring, if we don't want to limit ourselves 'teaching' Thomas (Friedman or Barnett), but not the big ' $\mathrm{P}$ ' who listened to them (and not to us). This can be terrain for the 'revenge' of political geographers.

\section{References}

Agnew, J. (2003). Contemporary political geography: intellectual heterodoxy and its dilemmas. Political Geography 22(6): 603-606.

Agnew, J. (2004). Is 'geopolitics' a word that should be endowed only with the meaning it acquired in the early twentieth century? Progress in Human Geography 28(5): 634-637.

Bassin, M. (2004). The two faces of contemporary geopolitics. Progress in Human Geography 28(5): 620-626.

Blomley, N. (2006). Uncritical critical geography? Progress in Human Geography 30(1): 87-94.

Cohen, S. B. (1964). Geography and politics in a world divided. London: Methuen.

Dalby, S. (1996). The environment as geopolitical threat: Reading Robert Kaplan's coming anarchy. Ecumene 3(4): 472-496.

Dalby, S. (2007). Regions, strategies and empire in the global war on terror. Geopolitics 12: 586-606.

Flint, C. (2003). Dying for a "P"? Some questions facing contemporary political geography. Political Geography 22(6): 617-620. 
Kaplan, R. D. (2009). The revenge of geography. Foreign Policy 172(may/june): 96-105.

Low, M. (2003). Political geography in question. Political Geography 22(6): 625-631.

Mamadouh, V. and G. Dijkink (2006). Geopolitics, international relations and political geography. Geopolitics 11: 349-366.

Newman, D. (2004). An informed and proactive geopolitics. Progress in Human Geography 28(5): 626-630.

O' Loughlin, J. (2000). Geography as space and geography as place. Geopolitics 5(3): 126-137.

O' Loughlin, J. and H. van der Wusten (1987). Back to the future of political geography. Professional Geographer 39(2): 198-199.

Ó Tuathail, G. (1987). Beyond empiricist political geography. Professional Geographer 39(2): 196-197.

Roberts, S., A. Secor, et al. (2003). Neoliberal geopolitics. Antipode 35(5): 886-897.

Sparke, M. (forthcoming). The world is not flat: Or, teaching Thomas about the geography of the world system. In N. Tanoukhi and D. Palumbo-Liu (eds.) World scale ambitions?. Durham, Duke University Press.

Toal, G. (2003). Re-asserting the regional: political geography and geopolitics in world thinly known. Political Geography 22(6): 653-655. 